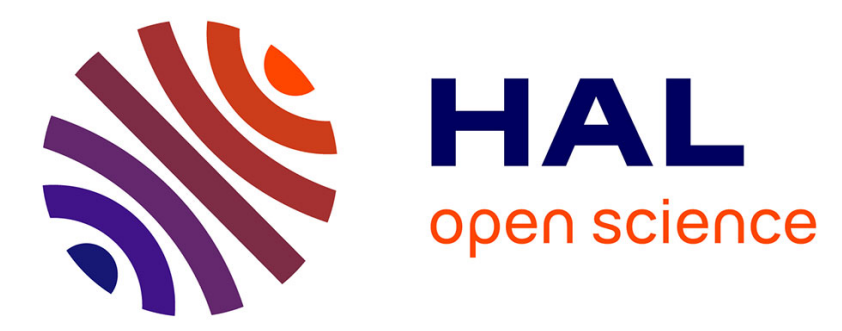

\title{
Crowd Engineering: Manage Crowd Contributions for Design and Manufacture of Innovative Products
}

\author{
Agostino Villa, Teresa Taurino
}

\section{To cite this version:}

Agostino Villa, Teresa Taurino. Crowd Engineering: Manage Crowd Contributions for Design and Manufacture of Innovative Products. 20th Working Conference on Virtual Enterprises (PRO-VE), Sep 2019, Turin, Italy. pp.93-102, 10.1007/978-3-030-28464-0_9 . hal-02478788

\author{
HAL Id: hal-02478788 \\ https://hal.inria.fr/hal-02478788
}

Submitted on 14 Feb 2020

HAL is a multi-disciplinary open access archive for the deposit and dissemination of scientific research documents, whether they are published or not. The documents may come from teaching and research institutions in France or abroad, or from public or private research centers.
L'archive ouverte pluridisciplinaire HAL, est destinée au dépôt et à la diffusion de documents scientifiques de niveau recherche, publiés ou non, émanant des établissements d'enseignement et de recherche français ou étrangers, des laboratoires publics ou privés. 


\title{
Crowd Engineering: Manage Crowd Contributions for Design and Manufacture of Innovative Products
}

\author{
Agostino Villa and Teresa Taurino \\ Politecnico di Torino, DIGEP - Department of Management and Production Engineering \\ Corso Duca degli Abruzzi 24, \\ 10129 Torino, Italy \\ \{agostino.villa, teresa.taurino\}@polito.it
}

\begin{abstract}
The increasing complexity of designing and manufacturing products as well as the growing speed required for their innovation is pushing large and medium-small companies to an ever-broader search for new ideas and for a wide availability of experts, able to provide timely contributions. Existing approaches mainly address the early phases of the product lifecycle in the frame of "open innovation". The crowd engineering approach is to organize an efficient and effective utilization of the "crowd", i.e. a wide set of persons, from students to private experts, and to start-ups and smart SMEs, which could be involved in the creation of innovative products. The first purpose of the paper is to give a presentation of Crowd Engineering in terms of a logical frame where crowd-workers will contribute into an informal collaborative network to fulfill technical and social needs. Then a schematic model based on an analogy between Crowd Engineering and Supply Relationship Management, will be outlined thus offering, on one hand, suggestions for a real implementation, on the other, some hints for a research agenda.
\end{abstract}

Keywords: Crowd Engineering, Combinatorial optimization model.

\section{Introduction}

A collaborative network is a network consisting of a variety of entities (e.g. organizations and people) that are largely autonomous, geographically distributed, and heterogeneous in terms of their operating environment, culture, social capital and goals, but that collaborate to better achieve common or compatible goals, and whose interactions are supported by computer networks [1]. In the last decades, the growing complexity of the design of new products, the increasingly shorter time-to-market required to market new products, and the spread of the so-called "augmented products" [2], i.e. products with constantly increasing services, is pushing companies, both large and medium-small, to an ever-broader search for ideas and innovations, through a wide availability of experts, able to provide timely contributions.

Consequently, companies need to re-engineer the design and production process, since many experts, companies, interested persons, associations, etc., which provide them with the many contributions that are usable, form a real "crowd". The Crowd 
Engineering builds social solutions of design and production of innovative products, by "empowering companies to turn the force of their crowds (suppliers, customers, partners and also employees) into business advantage" (https://www.definitions.net/definition/crowdengineering).

It is evident that such a re-engineering problem involves a careful selection of both the "Contributors" and the contributions themselves for the new product creation or production. This problem has been tackled with multi-criteria decision analysis approaches (MCDA), such as Analytic Hierarchy Process [3, 4] Analytic Network Process [5], Goal and Mixed-Integer Programming [6], Data Envelopment Analysis [7], and the Fuzzy Set theory [8]. However, little information is given about some feedback from practitioners and from implementations of such approaches, which are still few. In practice, as recently observed in some particularly innovative Mid-Small Enterprises (SME) registered in the PMInnova Program [9], the ongoing trend toward the individualization and even personalization of products results in new additional challenges for industrial enterprises in the frame of "open innovation" [10], i.e. with wide supports from externals.

To this scope, Crowd Engineering must set the following objectives:

- $\quad$ Establish new design approaches, strategies, methods and tools for the cocreation of innovative, individualized products by opening the product creation to the "crowd";

- Enable crowd-based product creation by next generation product data exchange, based on standards and open source;

- $\quad$ Realize an efficient procedure to collect, select, integrate contributions, such to obtain a good overlapping of the set of collaborative selected contributions and the desired scheme of the innovative product.

These three objectives can be achieved by developing the Crowd Engineering approach in a user-centric way, i.e. with a strong direction of the multi-dimensional design process implemented by an institution, institute or company, having a clear idea of the innovative product to be obtained and a considerable ability to define a "call for innovation creation" to a set of potential contributors.

The organization of the paper will be as follows. Section 2 is dedicated to give a preliminary logical overview of the Crowd Engineering concept and an outline of its structure. Section 3 first describes a schematic model of Crowd Engineering, based on the analysis of its analogy with the Supplier Relationship Management. Section 3 will present a schematic model of Crowd Engineering, by outlining the theoretical methods for supporting the multi-dimensional selection. Finally, Section 4 will present some hints of a research agenda, based on a Crowd Engineering work-flow scheme.

\section{Preliminary Logical Overviews of Crowd Engineering}

The Crowd Engineering procedure aims to focus, structure and translate into practice new ideas dedicated to collaborative co-creation. It is obtained from a process of collecting contributions from various sources (people, associations, SMEs, etc.), their selection and their integration for the purpose of conceptual and detailed design, the 
development of the necessary production operations, the production of new products oriented to the user. Crowd Engineering is based on the advancement of the wellknown triple helix towards a quadruple helix for innovation systems (see Fig. 1). The classic triple-helix from 1995 knows only three actors. But emerging innovations do not necessarily match consumer demand, so the helix has to be extended by a by a »user« component, involving end users/consumers in the innovation process. Therefore, additional attention has to be paid to community-based approaches, originated by "collaborative network", that appears to be powerful social frames for value creation [11].

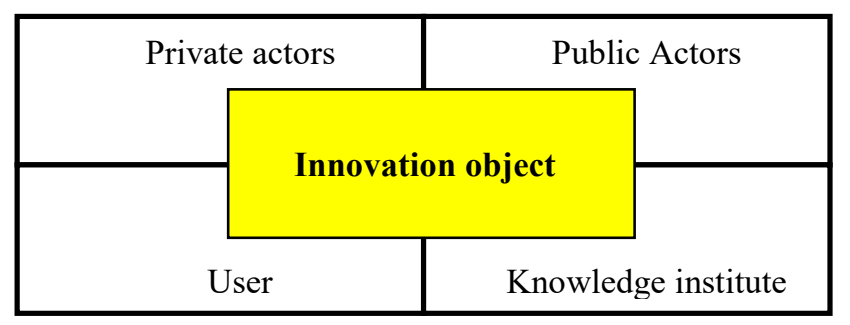

Fig. 1. Quadruple helix for innovation systems

Therefore, the Crowd Engineering project is stated by a "call for innovation creation" with the scope of searching and collecting contributions from many "Contributors" in order to integrate them so as to obtain a product (system or object) with characteristics of total novelty, structure and forms that allow production, all set by the Crowd Engineering Project Management (named in the following simply as "Manager"). The goal of the Crowd Engineering problem, as defined above, is advertised by the Manager in a broad way, in order to be able to receive contributions from many Contributors. Each Contributor proposes his own contribution, without knowing the contributions of the others or their participation in the research launched by the above mentioned "call". Therefore, the Contributors are potentially competitive. The Manager must have a "measure of usefulness" in order to verify if a contribution provided by an actor can be useful for the solution of the Crowd Engineering problem, in the sense that it can contribute to the achievement of the Crowd Engineering project objective. To this end, the Manager must evaluate each individual contribution obtained by each Contributors, and perform a multidimensional selection such as to collect only contributions with the following characters:

- A contribution must be "active" i.e. such to give rise to information/data that are coherent with some part of the innovative product or some operations that can contribute to the innovative product creation; this first attribute of a contribution can be evaluated according to the adopted measure of usefulness, above mentioned;

- Two or more contributions must be "collaborative", i.e. such to be usable in collaboration with other contributions, thus generating a more effective and active action in the design and production process; this further attribute of a pair of contributions can be evaluated by adopting a 
"measure of similarity" between the two contributions, with respect to the result of the "problem", that is to some part of the innovative product or to some innovative operation necessary to produce it.

From a simplified point of view, the Manager, once evaluated as useful the contribution will be, could consider a second different contribution to understand if the two contributions are collaborative: their joint use facilitates the achievement of the Crowd Engineering goal in a more efficient and effective way with respect to the individual ones. Once recognized a pair of collaborative contributions, the Manager will evaluate to support the couple with a third contribution, by estimating the joint use of the three in terms of an increasing - if any - of the measure of collaborative utility. Progressively, the Manager can reach a complete set of contributions, all complementary, such as to express an admissible solution for the Crowd Engineering project. The logical Crowd Engineering overview briefly described above, has the sole purpose of illustrating in a simplified way the concepts and methodology of the problem. Indeed, it makes evidence of the combinatorial nature of the contributions' selection problem.

\section{Schematic Model of Crowd Engineering}

A schematic model of the Crowd Engineering approach can be obtained by the analogy between the Crowd Engineering and the Supply Relationship Management (Section 3.1). This first analogy suggests taking also into account the evident links between Crowd Engineering and Crowdsourcing, as well as with "Collaborative Networks" (Section 3.2).

\subsection{Analogy between Crowd Engineering and Supply Relationship Management}

An enterprise performance, especially of small and medium-sized, largely depends on the relations with its suppliers, often belonging to different value chains, as in several industrial districts analyzed in $[12,13]$. Then, a good enterprise-suppliers relationship is a necessity for any industrial organization, to be able to respond to dynamic and unpredictable chains of the final products demand [14, 15]. Therefore, a Supplier Relationship Management (SRM) is a methodology that organizes all the interactions of the enterprise with third-party organizations, which supply goods and services in order to allow the best possible product creation [16]. The evaluation of a supplier is then the process of measuring the performance of the suppliers itself, as well as of its capability to meet the buyer (i.e. the enterprise) demands. Tacking now into account the above logical description of the Crowd Engineering approach, it is possible to identify a strong analogy between the two processes, as shown in Table 1 . Therefore, it is to use the SRM approach to give a schematic illustration of the Crowd Engineering procedure. 
Table 1. Correspondences between Crowd Engineering and Supply Relationship Management.

\begin{tabular}{|c|c|}
\hline $\begin{array}{c}\begin{array}{c}\text { Phases and Actors of Crowd } \\
\text { Engineering }\end{array} \\
\text { Enginering }\end{array}$ & $\begin{array}{c}\text { Phages and Actors of Supply } \\
\text { Relationship Management }\end{array}$ \\
\hline Actors: & Actors: \\
\hline$\overline{\text { Contributors }}$ & $\overline{\text { Suppliers }}$ \\
\hline $\begin{array}{l}\text { Manager (with clear view of the } \\
\text { innovation) }\end{array}$ & $\begin{array}{l}\text { Producer (with clear view of the final } \\
\text { product) }\end{array}$ \\
\hline Phase1. Identify contributions & Phase 1. Specify the purchase strategy \\
\hline $\begin{array}{cccc}\begin{array}{c}\text { Phase 2. Select the useful } \\
\text { contributions }\end{array} & & & \\
\end{array}$ & $\begin{array}{c}\text { Phase 2. Evaluate the supplier } \\
\text { performance }\end{array}$ \\
\hline $\begin{array}{l}\text { Phase } 3 . \text { Integrate the selected } \\
\text { contributions into the innovative product } \\
\text { description }\end{array}$ & $\begin{array}{l}\text { Phase } 3 . \text { Make collaborative- } \\
\text { integrated the Suppliers with respect to } \\
\text { the final product }\end{array}$ \\
\hline $\begin{array}{l}\text { Phase 4. Evaluate the global set of } \\
\text { contributions. }\end{array}$ & $\begin{array}{l}\text { Phase } 4 . \text { Evaluate the feedback from } \\
\text { the producer }\end{array}$ \\
\hline IF necessary, iterate & IF necessary, iterate \\
\hline
\end{tabular}

\subsection{Relations of Crowd Engineering with Crowd-sourcing and Collaborative Networks}

In order to make evidence of the strict relation between Crowd Engineering and Crowd-souring, the definition of the latter as reported in [17] is here referred to: "Crowdsourcing is the act of taking a job traditionally performed by a designated agent (usually an employee) and outsourcing it to an undefined, generally large group of people in the form of an open call." [18].

In practice, Crowdsourcing is a powerful tool because it describes collaborations both in research and in design actions which can significantly enlarge both the group of (potential) scientific partners, and the team of designers. With regards to the scientific context, Crowd sourcing implies to fist clearly identify the problem to be solved by the crowd, and then to plan a reasonable balance between natural antagonisms of contributors. Therefore, Crowdsourcing makes evidence of some important, and also critical aspects, of Crowd Engineering that, with respect to the former, now it appears to be the operative practical version. Referring now to relations between Crowd Engineering and Collaborative networks, among the different variety that the latter assumes in industry and services (see [19]), its aspect of "collaborative engineering" is concerning teams of technicians and engineers belonging to different companies and cooperating together on a common significant project, thus sharing skills and experiences, thus moving towards the creation of a "virtual community".

Therefore, the existence of a collaborative network is a very useful prerequisite for a company intending to start a Crowd Engineering project. In fact, the Collaborative network can become the area of first and fundamental diffusion of the "call for innovation creation", providing the most favorable environmental conditions for the launch of the Crowd Engineering project itself. A verification of this occurs in the 
next Session, where the operational scheme of a Crowd Engineering project is outlined, especially in the selection phase of the contributions and acceptance of the new ideas, two key phases of such a project.

\subsection{Crowd Engineering Operational Scheme}

As for SRM, also in case of Crowd Engineering, for an effective collaboration, Manager and contributors (i.e., suppliers of contributions for the innovation required by the Manager) need to share profits in order to achieve a win-win situation. To come to an effective and profitable collaboration/integration of contributions, a Crowd Engineering operational scheme is mandatory [20, 21, 22]. Such a scheme is illustrated in Fig. 2. It is just the representation of the Table of correspondences, being derived by SRM scheme illustrated in [3], but specifically adapted to the Crowd Engineering concept.

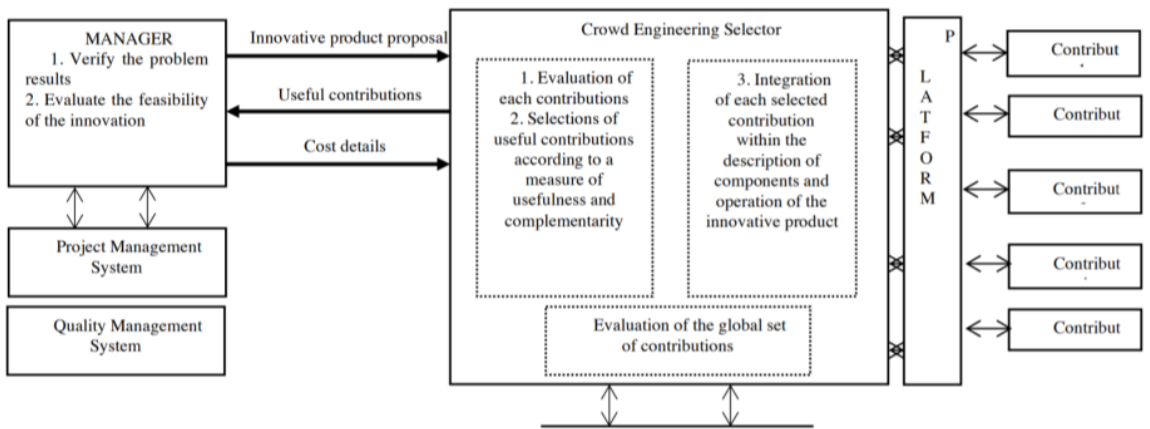

Fig. 2. The SRM-based scheme of the platform specifically adopted to the Crowd Engineering model.

The scheme is self-explanatory. The scheme inputs are the contributions sent by the "crowd", that is from the various types of suppliers of innovative ideas, in large numbers. The "heart" of the Crowd Engineering scheme is the Selector which, in accordance with the steps shown in the previous table, consists of the following parts:

(1) evaluation of each contribution and selection of each one useful among them by evaluating an associated "measure of usefulness" that represents the coherence of the contribution with the project goal and a "measure of complementarity" for each couple of contributions, as defined in Section 2 ;

(2) integration of each selected contribution within the description of the parts (components) and operations (of production) of the innovative product to be created;

(3) evaluation of the overall correspondence among the selected contributions and all the parts and all the operations of the innovative product.

The Manager is operating in the final block of the scheme, with the following aim:

(4) verifying the problem result, that is an admissible global correspondence among the selected contributions and all the parts and all the operations of the innovative product; 
(5) evaluate the real feasibility of the hypothesis of an innovative product obtainable from the integration, bearing in mind that different additions (with different uses of the contributions) are possible even though they obtain the same final product.

(6) evaluate costs and revenues in each case produces an innovative product among the feasible ones;

(7) evaluate the usefulness and the cost of every useful contribution received, to offer a profit to those who have helpfully responded to his call.

To implement its functions, the Manager receives as input:

- selected useful contributions;

- proposals for innovative products developed by the Selector.

It also interacts with the Warehouse Management System, for the needs of components, and with the Quality Management System, to estimate the performance of the resulting innovative products.

\section{Some Hints for a Research Agenda}

The development of the Crowd Engineering approach to select the best possible set of contributions from the "crowd" for innovative products creation, is one of the more challenging lines of evolution for smart enterprises.

To offer some considerations that could be utilized by experts when the needs for innovation become so important and critical for the survival of the enterprise, some ideas for the application of the Crowd Engineering approach is now presented, as a sequence of Work Phases (i.e. a Work-flow), summarized in the following Table 2. Indeed, a Manager needs to have a detailed description of the sequence of phases to be applied, starting from the definition and description of the innovative product desired, up to the Crowd Engineering organization and use.

Table 2. Outline of the Crowd Engineering workflow.

\begin{tabular}{|c|c|c|c|}
\hline$N^{\circ}$ & Scope & Description & Documentation \\
\hline $\begin{array}{l}\text { Work } \\
\text { Phase } 1\end{array}$ & $\begin{array}{l}\text { Call-for- } \\
\text { contributions, } \\
\text { referred to the a-priori } \\
\text { selected consumer } \\
\text { goods type. }\end{array}$ & $\begin{array}{l}\text { Definition of a } \\
\text { descriptive framework of } \\
\text { the a-priori selected } \\
\text { consumer goods type, } \\
\text { to be used as a reference } \\
\text { by: potential contributors, } \\
\text { i.e. people or organizations } \\
\text { - as above - who intend to } \\
\text { participate in the call, } \\
\text { sending their contributions. }\end{array}$ & $\begin{array}{l}\text { Document with } \\
\text { clear unambiguous } \\
\text { presentation of the } \\
\text { consumer goods } \\
\text { type. }\end{array}$ \\
\hline $\begin{array}{l}\text { Work } \\
\text { Phase } 2\end{array}$ & \begin{tabular}{lr}
\multicolumn{1}{c}{ Strategies } & to \\
manage the crowd of \\
contributors, \\
creating
\end{tabular} & $\begin{array}{l}\text { Policies, strategies and } \\
\text { initiatives in order to } \\
\text { leverage the crowd, that } \\
\text { means to gradually create }\end{array}$ & $\begin{array}{l}\text { (A)Communicati } \\
\text { on protocols, } \\
\text { managed by Crowd } \\
\text { Engineering }\end{array}$ \\
\hline
\end{tabular}




\begin{tabular}{|c|c|c|c|}
\hline & $\begin{array}{l}\text { "community } \\
\text { innovators". }\end{array}$ & $\begin{array}{l}\text { a "community of } \\
\text { innovators". Who will } \\
\text { send their proposals (data, } \\
\text { suggestions, project } \\
\text { indications)? }\end{array}$ & $\begin{array}{l}\text { Manager } \\
\text { B) Rules to } \\
\text { which participants } \\
\text { must satisfy in } \\
\text { defining and } \\
\text { formulating } \\
\text { contributions } \\
\text { (C) Clear rules } \\
\text { on the refusal of } \\
\text { contributions. }\end{array}$ \\
\hline $\begin{array}{l}\text { Work } \\
\text { Phase } 3\end{array}$ & \begin{tabular}{lr}
\multicolumn{1}{c}{ Methods } & for \\
accepting & and \\
selecting & \\
contributions & \\
depending on their \\
usefulness
\end{tabular} & $\begin{array}{l}\text { (a) Formulation and } \\
\text { presentation of the } \\
\text { structure of the "Crowd } \\
\text { Engineering Selector" to } \\
\text { guarantee an accurate, } \\
\text { clear and unambiguous } \\
\text { acceptance (or refusal) of } \\
\text { the contributions. }\end{array}$ & $\begin{array}{l}\text { (A) } \\
\text { Documentation } \\
\text { of the structure } \\
\text { of the "Crowd } \\
\text { Engineering } \\
\text { Selector" }\end{array}$ \\
\hline $\begin{array}{l}\text { Work } \\
\text { Phase } 4\end{array}$ & $\begin{array}{l}\text { Organizational } \\
\text { platform denoted } \\
\text { Crowd Engineering } \\
\text { Selector, for the } \\
\text { integrated } \\
\text { management of all } \\
\text { strategies, } \\
\text { initiatives and tool } \\
\text { utilizations }\end{array}$ & $\begin{array}{l}\text { Development of the } \\
\text { Platform dedicated to } \\
\text { managing all the } \\
\text { activities that will be } \\
\text { done for selecting, } \\
\text { evaluating and } \\
\text { integrating contributions. }\end{array}$ & $\begin{array}{l}\text { (A)Documentati } \\
\text { on of the Platform, } \\
\text { functionality } \\
\text { (B) } \\
\text { Authorizations of } \\
\text { all contributors to } \\
\text { include their data, } \\
\text { info's and } \\
\text { contributions in the } \\
\text { Platform }\end{array}$ \\
\hline $\begin{array}{l}\text { Work } \\
\text { Phase } 5\end{array}$ & \begin{tabular}{l}
\multicolumn{2}{r}{ Impact evaluation } \\
of the Crowd \\
Engineering \\
application
\end{tabular} & $\begin{array}{l}\text { Analysis of the Platform } \\
\text { applications to pilot case, } \\
\text { such as their } \\
\text { correspondence with the } \\
\text { product tree graph nodes } \\
\text { and links. }\end{array}$ & $\begin{array}{l}\text { (A) Data and } \\
\text { information } \\
\text { gradually gathered } \\
\text { and cataloged in } \\
\text { order to describe } \\
\text { the result. }\end{array}$ \\
\hline
\end{tabular}

This simplified workflow suggests some hints for future research lines in which a comprehensive view of the Crowd Engineering, Crowd-sourcing and Collaborative network could contribute to a real innovation of the creation process of new products.

According to [17], some main research lines can be envisaged, for assuring a useful and significant development of Crowd Engineering and its practical implementation in industrial and service frames:

a) identification of robust methods to identify and select fruitful contributions for a given innovation project goal, such to be clearly transferred to the crowd and understood by each potential contributors; this will characterize the communication power from the innovation project Manager and the wide 
range of individuals and entities that could give really new ideas, in a form to be recognized and integrated by the Manager itself;

b) selection and clear communication of incentives (or earnings) for the individual contributors, clearly related to the usefulness of the contribution and its integration with the rest, and finalization to the goal of the project;

c) promotion of healthy competition among contributors, while preserving the anonymity of contributions and guaranteeing their ownership, especially as the project takes shape and the integration of contributions will become increasingly evident (as is the exclusion of contributions of little value or not useful);

d) the correct evaluation (above all in economic terms) of the theoretical contributions and their validation, especially in the case of particularly innovative contents; similar considerations apply to the evaluation of contributions with a rapid practical impact;

e) Finally, the organization of a structure for managing the interactions of the Manager (or project team) with the crowd, through a structure that manages the center-contributor relations clearly but preserving the privacy of each one.

Acknowledgments. This research has been developed in the context of the PMInnova Program (www.pminnova.eu).

\section{References}

1. Luis M. Camarinha-Matos \& Hamideh Afsarmanesh (July 2007). "A Comprehensive Modeling Framework for Collaborative Networked Organizations". Journal of Intelligent Manufacturing. 18 (5): 529-542

2. Browne J. et al, RFID in product lifecycle management: a case in the automotive industry, International Journal of Computer Integrated Manufacturing. Volume 22, 2009 - Issue 7: 616-637 (2009)

3. Seminathan MV., Hemamala K., Analysis of Supplier Relationship Management Model using AHP https://www.amrita.edu/sites/default/files/analysis-of-supplierrelationship-management-model-using-ahp.pdf

4. Schniederjans, M. J., \& Garvin, T. Using the analytic hierarchy process and multiobjective programming for the selection of cost drivers in activity-based costing. European Journal of Operational Research, 100(1): 72-80 (1997)

5. Meade Laura M. and Adrien Presley, R\&D Project Selection Using the Analytic Network Process. IEEE Transactions on engineering management. 49(1): $59-66$ (2002)

6. Selen, W. \& Hott, D. J Oper Res Soc 37: 1121. https://doi.org/10.1057/jors.1986.197 (1986)

7. Cooper W.W., Seiford L.M., Zhu J. Data Envelopment Analysis. In: Cooper W.W., Seiford L.M., Zhu J. (eds) Handbook on Data Envelopment Analysis. International Series in Operations Research \& Management Science, vol 71. Springer, Boston, MA (2004)

8. Deschrijver Glad, Etienne E. Kerre, On the relationship between some extensions of fuzzy set theory, Fuzzy Sets and Systems, Volume 133, Issue 2, Pages 227-235, ISSN 0165-0114, https://doi.org/10.1016/S0165-0114(02)00127-6 (2003) 
9. PMInnova Program, agremento Politecnico di Torino - Gruppo Bnca di Asti, A. Villa Responsible, see: www.pminnova.eu (2018)

10. Oliver Gassmann O., Enkel E., Chesbrough H., The future of open innovation. R\&D Management, Volume 40, Issue3, 213, 221 (2010)

11. Camarinha-Matos L., Afsarmanesh H., "A Comprehensive Modeling Framework for Collaborative Networked Organizations". Journal of Intelligent Manufacturing. 18 (5): 529-542 (2007)

12. Taurino Teresa. Using collaboration management in industrial clusters - case study of Italian energy cluster. 9(4): 138 - 149 (2018)

13. Villa Agostino and Teresa Taurino. From industrial districts to SME collaboration frames, International Journal of Production Research, 56:1-2, 974-982, DOI: 10.1080/00207543.2017.1401244 (2018)

14. Antonelli D., Bruno G., Taurino T., Villa A. Conditions for Effective Collaboration in SME Networks Based on Graph Model. In: Camarinha-Matos L.M., Scherer R.J. (eds) Collaborative Systems for Reindustrialization. PRO-VE 2013. IFIP Advances in Information and Communication Technology, vol 408. Springer, Berlin, Heidelberg (2013)

15. Antonelli D., Bruno G., Taurino T., Villa A. Graph-based models to classify effective collaboration in SME networks. International Journal of Production Research, vol 53, Issue 20, pp: 6198 - 6209, https://doi.org/10.1080/00207543.2015.1038368 (2015)

16. Chandra, C., \& Kumar, S. Supply chain management in theory and practice: a passing fad or a fundamental change? Industrial Management \& Data Systems. 100(3): 100114 (2000)

17. Buecheler T., Sieg J.H., Fuckslin R.M., Pfeifer R., Crowdsourcing, open innovation and collective intelligence in scientific method: a research agenda and operational framework, in Proc. Alife XII Confence, Odesse, Denmark, 679-686 (2010).

18. Howe J., Crowdsourcing. Why the power of the crowd is driving the future of business, see: http://www.crowdsourcing.com/ (2010)

19. Camarinha.Matos L., Afsarmanesh H., Collaborative networks in industry and services: research scope and challenges, Symp. Cost Oriented Automation, La Habana, Cuba (2007).

20. Viroli M., J. Beal, F. Damiani and D. Pianini, "Efficient Engineering of Complex Self-Organising Systems by Self-Stabilising Fields," IEEE 9th International Conference on Self-Adaptive and Self-Organizing Systems, Cambridge, MA, 2015, pp. 81-90. doi: 10.1109/SASO.2015.16 (2015)

21. Groen E.C., Doerr J., Adam S. Towards Crowd-Based Requirements Engineering A Research Preview. In: Fricker S., Schneider K. (eds) Requirements Engineering: Foundation for Software Quality. REFSQ 2015. Lecture Notes in Computer Science, vol 9013. Springer, Cham (2015)

22. Snijders R., F. Dalpiaz, M. Hosseini, A. Shahri and R. Ali, "Crowd-centric Requirements Engineering," IEEE/ACM 7th International Conference on Utility and Cloud Computing, London, 2014, pp. 614-615. doi: 10.1109/UCC.2014.96 (2014) 